\title{
Chinese and the United Kingdom's Primary School Teachers' Approaches to Discipline in Class
}

\author{
Guan Junyan \\ Editorial Office, Nanjing Normal University, Nanjing, China \\ Email: 1834288422@qq.com
}

\begin{abstract}
This study was designed to compare the similarities and differences between Chinese and the UK's primary school teachers' approaches to discipline problems. It also investigated the factors that influence the teachers' choices on different aspects of discipline. Moreover, the study was to discuss the reasons that cause the similarities and differences between the two countries.

Questionnaires were carried out with 75 teachers working for the different primary schools as well as 45 teachers in the UK's primary schools.

Findings showed that factors such as different teaching subject, teaching experience, the characteristics of class of teacher teach and individuals and so on may influence teachers' choices on solving discipline problems. There are many similarities and differences on the different aspect on teachers' approaches on discipline in China and the UK, but similarities are more than differences. The beliefs of children and children's behaviours, globalization, culture, education system and practice situation in two countries may cause the similarities and the differences.

The implications of these findings are that teachers should pay attention to students' self-esteem and treat the solution of punishment in the right way.
\end{abstract}

Keywords: Chinese and the UK's primary school teachers, discipline problems, teachers' approaches

\section{Introduction}

School, plays an important role in children's development in their life. "Young people spend 15000 hours in school, which provides a significant time frame in which they can learn" (Mortimore et al. 1998, Rutter 1983, Rutter \& Maughan, 2002, as cited by Porter, p3). Indeed, school features may have a more direct effect on students' academic progress and behaviour than other group such as family, community. Rutter and Maughan (2002) did a research which indicates that schools account for between 20 and 25 per cent of factors in student progress, with family factors explaining only 5 per cent. Classroom is a key ingredient of school. Therefore, Sylva (1994) suggested that classroom factors might be even more influential than aspects of the school. These findings confirm that teachers' influence on children's behaviours in schools, or rather, in class.

"Classroom discipline has been a continuing concern of both educators and the public over the past twenty years, and not without reason" (Hartzell \& Petrie, 1992, pp376). For teachers, discipline problems influence their ability to do their job, cause their stress, destroy the public image of them, and, more seriously, lead to fear (Bauer, 1985; Elman et al, 1991; Johnson \& Bany, 1970). Therefore, teachers pay attention to discipline problems. Accordingly, there are varieties of methods to maintain discipline such as warning or punishment by teachers. However, there are questions about some factors that may influence teachers' views or behaviours in different aspects of discipline such as their goals of maintaining discipline. Furthermore, finding out the similarities and differences between the UK and Chinese primary school teachers' approaches to discipline seems to be meaningful. China and the UK, have the different education system, although both of them have long educational history. To China, the UK, as a western country that has a different culture and educational background, teachers' strategies for maintaining discipline may show many differences. In addition, the UK's education has a long history and is worldwide famous. These outstanding education ideas and methods are attractive to Chinese educators. To the UK, perhaps many people's ideas about Chinese education stay for last decades such as much homework, physical punishment. Yu (2007) pointed out that most Chinese teachers were used to controlling the class to restrain children's behaviours before $90 \mathrm{~s}$, while in recent 
years, educators and teachers begin to change their ideas. They give children more freedom, and weaken the controlling to children. Chinese educational department banned physical punishment in schools in 1995 (Liu, 2000). More and more primary schools need the high education teachers. A statistic by Xu (2001) demonstrated that there were 92 per cent primary teachers in Beijing owned undergraduate or postgraduate diploma. Therefore, it is worth to discuss that the reasons which cause the differences between the two countries' on the aspect of discipline.

In the context, the study includes three research questions. Firstly, which factors influence teachers' choices on the different aspects of discipline? Secondly, what are the similarities and differences between UK's and Chinese primary schools in dealing with the discipline problems? Thirdly, what cause the similarities and differences between the two countries?

All of the questions want to be answered need the teachers' views and behaviours in term of discipline. Questionnaires are processed in both the UK's and Chinese primary schools. The samples of questionnaires are 135 copies, which make up of 85 Chinese copies and 50 the UK's copies.

This study attempts to compare the UK's and Chinese primary school teachers' approaches to discipline in the class. It aims to identify the differences and similarities between these two groups of teachers. The study also examines the reasons that cause the diversity and teachers' different choices. The study highlights implications and makes recommendations for the discipline research field, the implication of the discipline in Chinese primary education as well as for primary education in the context of UK.

\section{Analysis of Questionnaires in China and the UK}

In total 135 copies of the questionnaires were distributed, but, 125 copies were received. Among the received questionnaires, the effective ones are 120 copies while another 5 copies do not work. The omission of questions causes the ineffective questionnaires. The effective questionnaires include 75 copies of Chinese questionnaire and 45 copies of the UK's questionnaire. This part will analyze and discuss the findings in every question both of Chinese and the UK's questionnaires.

\subsection{Teachers' Gender, Experience and Age of Children Taught}

Table 1. Teachers' gender, experience, age of children taught and teaching subjects

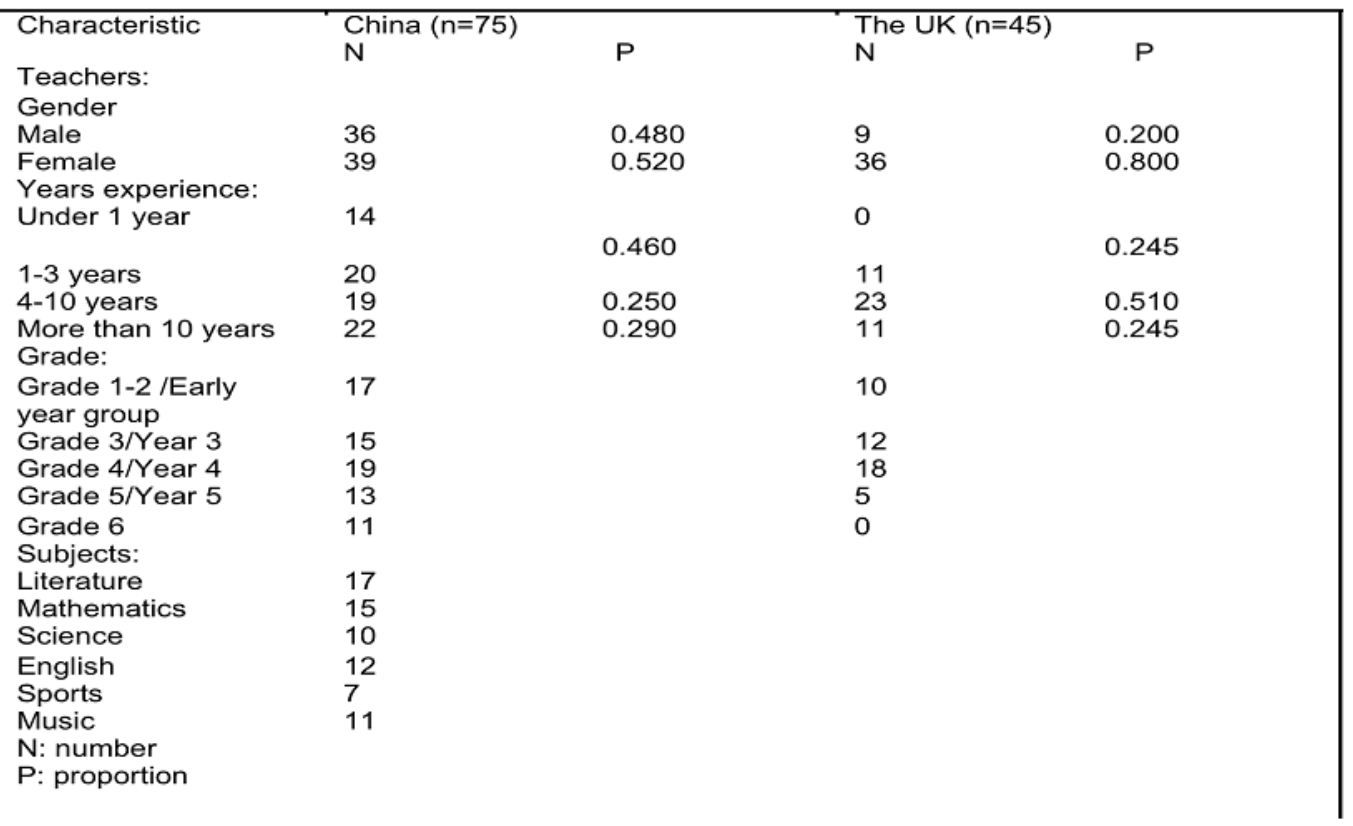

Question 1-3 can be called as basic questions in questionnaires. It refers to the information about teachers' gender and experience, age of children taught. In China, the distribution of students in 
different year groups is divided into grade. Generally speaking, children in contemporary grade are one year older than in last grade, from grade one to grade six. In addition, there are different subjects for children to learn in Chinese primary school. In other words, teachers teach their own subjects such as literature, mathematics, English, science, sports, music and so on. These two aspects are different from the UK. Perhaps they are the divergences on the aspect of two countries' educational system, therefore, it is difficult to judge which one is better or not.

The three questions aim to collect the basic and necessary information of respondents, then look for the relation between these basis information and the questions subsequently in the following.

Among the respondents of Chinese primary schools, the numbers of male and female teachers are nearly equal, which is a very different gender balance to that seen in the UK. The primary teaching is a predominantly female profession in the UK, which can be seen from the data of questionnaires- 36 females and 9 males (see table 1).

In terms of teaching experiences, the new teachers (under 3 years' experience) make up nearly a half of Chinese respondents, whereas the same group in the UK only occupies nearly a quarter (see table 1).

\subsection{The Goals of Maintaining Discipline}

According to the different theories of discipline, there are four popular kinds of goals. They are AEstablishing, maintaining and reinstating order; B- compliance or obedience; C- Helping students establish self-discipline; D- Emotion regulation (teaching students to express their feeling appropriately, without getting themselves distressed or upsetting surrounding people); E- others (see appendix 1). They can be linked to the theory of applied behaviour, assertive discipline, cognitive, humanism in the chapter 2 .

First of all, it will analyze the goals and teachers' experiences. For the Chinese teachers of experience that under 1 year and 1-3 years (it is considered as new teachers in this study), there are nearly $79 \%$ and $40 \%$ of them choosing A- "establishing, maintaining and reinstating order". About $73 \%$ of more than 10 years' experience teachers and $42 \%$ of teachers who have taught 4-10 years maintain discipline for the purpose of C- "helping students establish self-discipline" (see chart 1). In conclude, it is possible that the Chinese teachers who have long teaching experience maintain discipline mostly on the aspect of students, whereas the new teachers emphasis on their teaching environment.

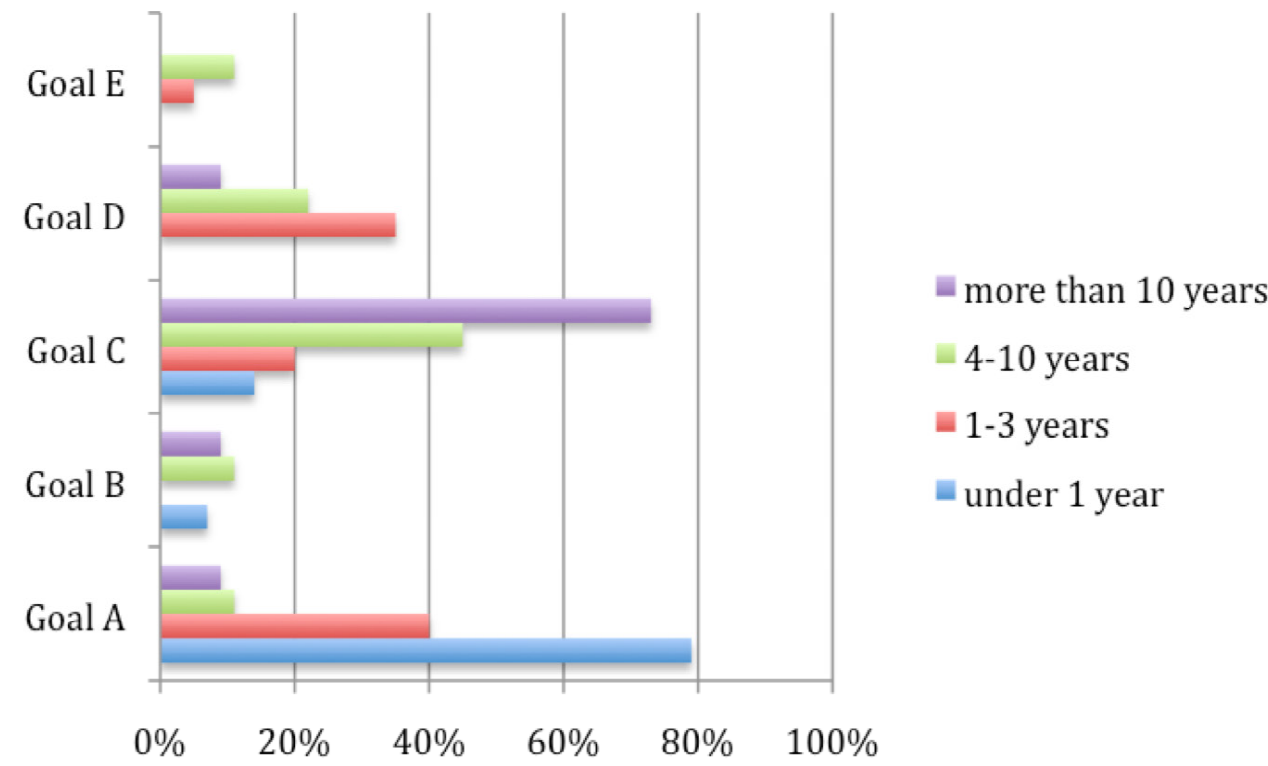

Chart 1. The choices of goals and teachers' experience (China)

Secondly, it will analyze the goals and teaching subjects in China. According to D- "Emotional regulation (teaching students to express their feeling appropriately, without getting themselves distressed or upsetting surrounding people), Chinese teachers who teach music (7 of 11) and sports (4 of 
7) almost choose this option (see table 2). On the other hand, teachers who teach other 5 subjects prefer A- "Establishing, maintaining and reinstating order" and C-"Helping students establish self-discipline" (see table 2). Furthermore, there are two teachers who give two different opinions, one of them wrote down "let students happy" and the other one suggested that the goal for maintaining discipline is cultivate students' temperament. Both of the teachers teach music (see table 2).

Table 2. The choices of goals and teaching subjects (China)

\begin{tabular}{cccccccc}
\hline Goals & \multicolumn{7}{c}{ teaching subjects } \\
\cline { 2 - 7 } & literature & mathematics & English & science & sports & literature & mathematics \\
\hline Goal A & 8 & 3 & 4 & 6 & 1 & 8 & 3 \\
Goal B & 2 & 0 & 2 & 0 & 1 & 2 & 0 \\
Goal C & 10 & 12 & 6 & 4 & 1 & 10 & 12 \\
Goal D & 0 & 0 & 0 & 0 & 4 & 0 & 0 \\
Goal E & 0 & 0 & 0 & 0 & 0 & 0 & 0 \\
Total & 20 & 15 & 12 & 10 & 7 & 20 & 15 \\
\hline
\end{tabular}

Therefore, the different subjects may influence teachers' goals of maintaining discipline. Compared with other subjects, the classes of music and sports are flexible and active. The contents often include singing, playing drama, playing games or other athletic activities. Teachers cannot carry out a series of activities if they emphasis on keeping good order. Therefore, in these classes, teachers do not focus on restraining children's behaviours. They pay attention to children's emotion. The similarity of these two subjects is the activities can help students venting of emotion, in the context of not disturbing or upsetting surrounding people. For example, in sport class, students can express their feeling by attending athletic activities.

For the UK's primary school teachers, most of teachers (30) believe that C- "Helping students establish self- discipline" are their goals for maintaining discipline in class. The extra 10 teachers regard $\mathrm{D}$ as their goals. There are 5 teachers giving the different ideas of the goals. These ideas can be summarized as the goals of maintaining discipline in class is changing anytime, perhaps minutes to minutes or day to day or anything else. No one choose A- "Establishing, maintaining and reinstating order" or B- "Compliance or obedience", which is a significant difference from China. For the UK's teachers, teaching young people setting up self-discipline becomes the largest group of the goals, which is similar to China. It seems that there is no certain relationship between the teachers' teaching year group and the goals or between the teaching experience and the goals, as a very high percents of teachers in all group choose C- "Helping students establish self-discipline" (see chart 2). In addition, because most of the teachers maintain discipline on the aspect of self-discipline, the relation between the choices of goals and teaching experience in the UK's respondents is little (see chart 3), which is also different from China.

To sum up, the similarities between China and the UK on discipline goals refer to the choices of selfdiscipline. The number of teachers who choose C- "Helping students establish self- discipline" is the largest, although most of teachers who choose this option in China are teachers of long experience. The differences can be concluded as follows. First of all, teachers' experience and teaching subjects influence Chinese teachers' choices, whereas it is not true in the UK. For example, most of Chinese new teachers choose A- "Establishing, maintaining and reinstating order". In contrast, none of the UK's teachers choose this goal, which is a significant diversity between the two countries. Overall, the most important factor in explaining variation in the teachers' goals is the different country they teach. 


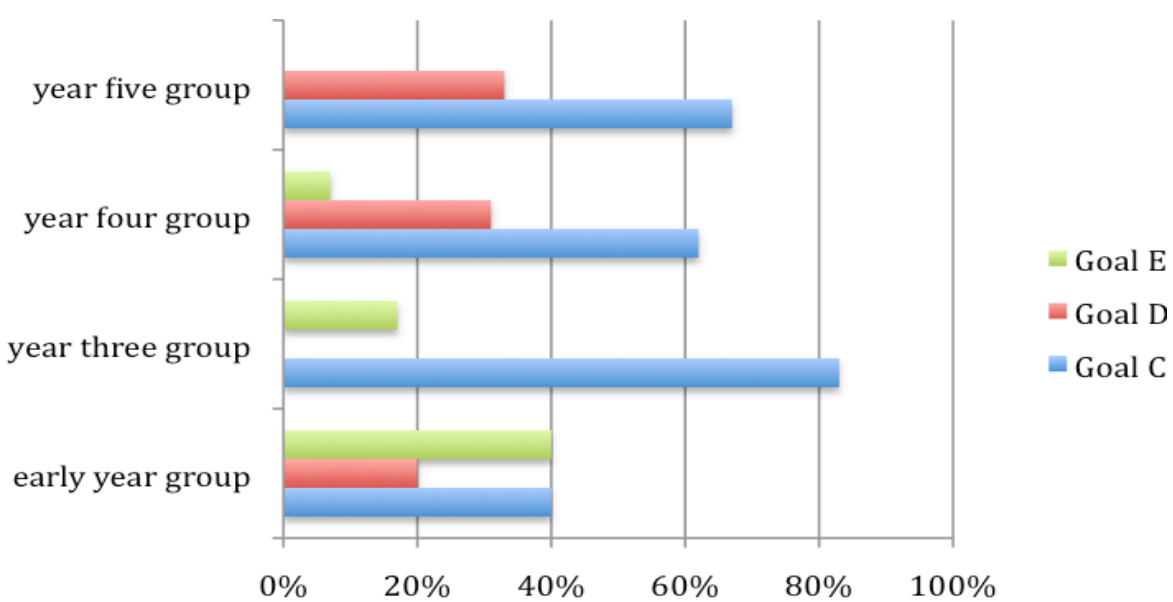

Chart 2. The goals and the numbers of teachers who teach different year group (the UK)

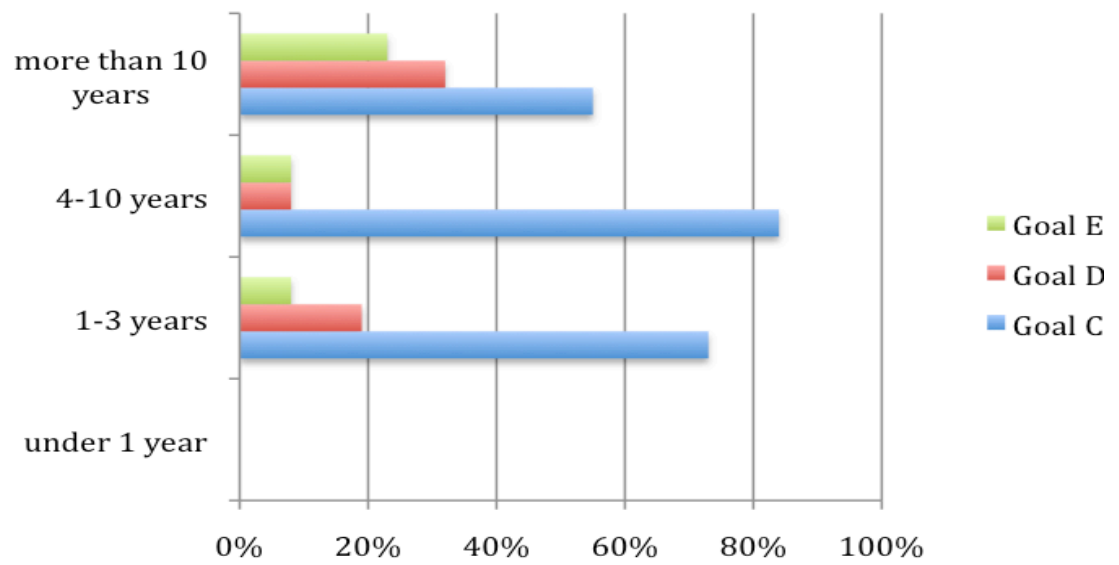

Chart 3. The choices of goals and teaching experience (the UK)

\subsection{The Behaviours that Are High Priorities for Teachers to Correct in Class}

For A-Not being quiet when teacher is talking, it occupies the most votes both in China and the UK (see table 3). Perhaps this behaviour may be easier to influence others, compared with some behaviours such as arriving late and not bringing equipments. No one in China and the UK choose the two kinds of behaviours. As Roger's views in chapter 2, the behaviours that disrupt the learning of anyone or the whole group are more serious. The pupils around the talking children may pay attention to his or her talking contents, leading to distraction. On the other hand, this behaviour may influence the process of teachers' pedagogical activities. Teachers cannot explain instructions to everyone or let every child listen to their requirements if there was one or some children who cannot keep quiet when they are talking.

According to B-'messing about' with another pupil or pupils, it is the high priorities for the UK's teachers to correct. However, it is not a serious problem for Chinese teachers. In fact, this behaviour is very impolite and needs teachers' attention. Perhaps in China, this behaviour is less in class. Or it often happens out of the class so that teachers cannot pay attention to. The similar phenomenon happened on the option E- Calling out/ shouting across the classroom and H- bullying. However, they are opposite of the choices on option B, as it is a high priority for Chinese teachers to correct instead of the UK's teachers

For F-Not getting down to work when asked to do so, it is a high priority for teachers to correct in class. As the same as A- not being quiet when teacher is talking, it is also a behaviour that may influence others by disruptive. Therefore, both the Chinese and the UK's teachers emphasize on children's behaviours that may disturb other pupils or the whole group. In contrast, the behaviours that seem not to violate other's right are considered as fairly inferior. It verifies Roger's views in Chapter 2. 
As for J- Cheek, there is a vast diversity between two countries' teachers. Chinese teachers treat it as the second serious behaviours for them to correct, whereas it seems no importance for the UK's teachers. Perhaps this behaviour is rude and challenges their authority to a large extent for Chinese teachers. Compared with other countries, China emphasizes on the authority of old people and teachers more in the culture. Therefore, Chinese teachers may consider it very serious and they cannot bare it when this behaviour happens to them. It is possible that this is why most of Chinese teachers do not pay attention to the other rude behaviours such as B- an impolite behaviour among children. Perhaps this impolite and rude behaviour is also not permitted in the UK. However, the reflection of them may be less than Chinese teachers. It is the difference in the two countries' culture. Furthermore, the other reason may be that cheek does not always happen in the UK's primary schools.

Table 3. The behaviours that are high priorities for teachers to correct

\begin{tabular}{lll}
\hline \multicolumn{1}{c}{ Behaviors } & \multicolumn{2}{c}{ Numbers of choices } \\
\cline { 2 - 3 } & China & The UK \\
\hline A. Not being quiet when teacher is talking & 52 & 32 \\
B. 'Messing about' with another pupil or pupils & 12 & 20 \\
C. Arriving late to the lesson & 0 & 0 \\
D. Not bringing equipment & 0 & 0 \\
E. Calling out/ shouting across the room & 45 & 8 \\
F. Not getting down to work when asked to do so & 30 & 24 \\
G. Inappropriate/ offensive remarks & 9 & 12 \\
H. Bullying & 30 & 14 \\
I. Cheek & 49 & 3 \\
J. Others & 0 & 0 \\
\hline
\end{tabular}

\subsection{Discipline Time}

Nearly seventy-five per cent of Chinese teachers (56 teachers)spend 1-5 minutes on discipline in one class. In contrast, about eighty-seven (39) per cent of the UK's teachers spend 1- 5 minutes on discipline. Therefore, both Chinese and the UK's teachers do not spend much time on discipline compared with other teaching activities. Perhaps the main purpose of the class is other teaching activities, discipline is used for creating a good learning atmosphere. Sixteen per cent teachers (12) do not cost any time in maintaining discipline in class, while there is not any of the UK's teachers choosing this option. However, the accuracy of the phenomenon in Chinese questionnaire should be verified. There are approximately nine per cent of UK's teachers (6) and Chinese teachers (7)spending 6-10 minutes on discipline.

\subsection{The Approaches that Teachers Presently Use or Are Familiar With}

As concerned to approaches of A- ignoring the problem, there are a very small number of Chinese teachers who presently use or are familiar with. However, no one in the UK chooses this option (see table 4). For responding to students' disruptive behaviours, most of Chinese and the UK's teachers both remind the students by B- eye contact (see table 4). Eye contact looks "warm" solution for students, because it is the communication between teacher and the student of misbehaviour. Meanwhile, it may not influence other pupils or the process of the class. According to calling names $(\mathrm{C})$ and pointing out their behaviours (D), Chinese teachers prefer these two approaches while the UK's teachers almost do not use them in class, which is a significant difference. In contrast, the UK's teachers always change student's seat (E) nearby them to solve the discipline problem. Although Chinese teachers also use this method, the UK's teachers prefer it. Therefore it seems that Chinese teachers are used to solve discipline problems by direct warning such as name calling, pointing out the behaviours in class, while the UK's teachers pay attention to students' self-esteem.

According to F- talking to the students after class, the UK's teachers always use it, whereas Chinese teachers tend to solve the problems in class. It is possible that Chinese teachers want to give an example 
in class to remind other pupils not to break the rules again. However, the UK's teachers solve the problem by knowing more about children's behaviours in class such as the reason, the real situation. Because sometimes, what the teachers looked is not the actual incident that happed. Therefore, teachers should judge children's behaviours and evaluate it whether they need to point out in class right now.

Another result is that no Chinese teachers presently use punishing in any form to maintain discipline, although punishing was popular in Chinese education in the last decades. It seems unbelievable and should be verified in the observation. Teachers in the UK may punish children when they disturb the discipline (see table 4 ).

Table 4. The approaches that teachers presently use or are familiar with

\begin{tabular}{lll}
\hline \multicolumn{1}{c}{ Behaviors } & \multicolumn{2}{c}{ Numbers of choices } \\
\cline { 2 - 3 } & China & The UK \\
\hline A. Nothing, ignoring the problem & 10 & 0 \\
B. Reminding the students by eye contact & 65 & 40 \\
C. Reminding the students by calling his or her names in class & 40 & 10 \\
D. Reminding the student by pointing out their misbehaviors & 60 & 5 \\
E. Asking the students to sit near the teacher & 30 & 34 \\
F. Talking to the students after class & 18 & 27 \\
G. Punishing the students to write down the rules & 0 & 5 \\
H. Punishing the students not to play at the time of playing & 0 & 4 \\
I. Calling the student's parents & 10 & 0 \\
J. Others & 0 & 5 \\
\hline
\end{tabular}

\subsection{The Most Effective and Ineffective Approaches on Discipline}

Table 5. The most effective and ineffective approaches on discipline

\begin{tabular}{lllll}
\hline \multirow{2}{*}{ Approaches } & \multicolumn{3}{c}{ Numbers of choices } \\
\cline { 2 - 5 } & \multicolumn{2}{c}{ Most effective } & \multicolumn{2}{c}{ Most ineffective } \\
\cline { 2 - 5 } & China & The UK & China & The UK \\
\hline A. Nothing, ignoring the problem & 0 & 0 & $75(100 \%)$ & $45(100 \%)$ \\
B. Reminding the students by eye contact & $30(40 \%)$ & $23(51 \%)$ & $12(16 \%)$ & $3(7 \%)$ \\
C. Reminding the students by calling his or her names in class & $40(57 \%)$ & $2(4 \%)$ & $10(13 \%)$ & $13(29 \%)$ \\
D. Reminding the student by pointing out their misbehaviors & $22(29 \%)$ & $1(2 \%)$ & $3(4 \%)$ & $17(38 \%)$ \\
E. Asking the students to sit near the teacher & $18(24 \%)$ & $19(42 \%)$ & $5(7 \%)$ & $1(2 \%)$ \\
F. Talking to the students after class & $2(3 \%)$ & $14(31 \%)$ & 0 & 0 \\
G. Punishing the students to write down the rules & 0 & 0 & $24(32 \%)$ & $6(13 \%)$ \\
H. Punishing the students not to play at the time of playing & 0 & $2(4 \%)$ & $27(36 \%)$ & $3(7 \%)$ \\
I. Calling the student's parents & $2(3 \%)$ & 0 & 0 & 0 \\
J. Others & 0 & $5(11 \%)$ & 0 & 0 \\
\hline
\end{tabular}

According to the most effective approaches to discipline, there are no Chinese or the UK's teachers choosing A- ignoring the problem (see table 5). Accordingly, all of the teachers treat it as the most ineffective approach to discipline. As for B- eye contact, it is effective for Chinese and the UK's teachers, even receive the most votes in the UK's questionnaires. For name calling and pointing the behaviours in class, they are two kinds of most effective approaches for Chinese teachers. Among them, calling students names is the most effective approaches. However, these two effective approaches change to the most ineffective approaches for the UK's teachers. Referring to the question of teachers' common approaches to discipline, these two approaches are mostly used by Chinese teachers and hardly chosen by the UK's teachers. Therefore, this finding can be related to that one.

Changing student's seat to near the teacher seems effective for both countries' teachers, although it is more effective for the UK's teachers (see table 5). Talking to students after class is also one of the most effective approaches for the UK's teachers, while it is less effective for Chinese teachers. No one of 
Chinese teachers choose punishment such as $\mathrm{G}$ and $\mathrm{H}$ as the most effective approaches while they consider punishment as the most ineffective approaches. In contrast, there are the UK's teachers who believe the effect of punishment, even though the number is limited. However, there are a small number of the UK's teachers who treat punishment as the most effective approaches, compared with Chinese teachers. Punishment becomes a special choice for Chinese teachers.

According to the UK's teachers, a small group of them give the other effective approaches. They can be summarized as praising others nearby for good behaviours. In other words, they pay attention to the role of good examples. They hope peers can influence each other on discipline.

\subsection{Discipline Plan and Chinese Teachers' Feeling of Their Approaches to Discipline}

As to the discipline plan, there are no Chinese teachers making it. So all of the respondents answer question 12, which refers to the feeling of their approaches to discipline in pupil's learning. The answerers can be summarized to five types.

The first one is drawing lesson from failure. Some teachers ignored children's discipline problems at beginning. At last, they found that the problems became more serious. This is because more and more young persons join the "activities" of disturbance. Under the circumstance, these teachers change their attitudes from ignoring to attention to it.

The second one focuses on the relation between interesting teaching material and discipline. The group of teachers wants to attract children by keeping the interest of the class from the first minutes to the last, however, it seems difficult.

Thirdly, teachers consider that they are patient to children for their misbehaviours that break discipline. The concrete solutions that the teachers apply are considering children's feeling. For example, do not call children's names and point out their misbehaviours in class, do not punish them miss the chance of playing after class. However, calling names and pointing out children's misbehaviours are the two most effective approaches for many teachers in the previous question.

Fourth, teachers reinforce the affect of good examples to train self-discipline. Teachers can give them more praise and positive guidance. In this way, children feel that they turn to be the good example for other pupils or they are the good guys in teachers' opinion. So they will reinforce the ability of selfdiscipline.

Fifth, a group of Chinese teachers have their own requirements at the beginning of every class. In their practice, it can reduce the discipline problems to some extent.

The last one refers to discipline plan. Although there is no Chinese teachers have discipline plan, yet a part of them consider that it is necessary for them to making discipline plan. They have their own strategies on approach to discipline.

\subsection{Discipline Plan of the UK's Teachers and Their Feeling about Approach to Discipline}

For the UK's teachers of having the discipline plan, their practice can be described as follows.

1. Children make their own rules. For example, they make a contract for behaviour. Specifically, teachers ask children list some important points that they consider as important. Children should obey them, as they are their own rules. Young people also sign their names and this copy of rules means taking effect.

2. Warning system. This system is divided into three aspects. $1^{\text {st }}$ : warning initially on board; $2^{\text {nd }}$ : yellow warning- moved away from class/group; $3^{\text {rd }}$ :red warning- miss playing- all or some.

3. Following school behaviour policy. In this context, the whole school have a behaviour policy which is followed by all adults in the responders' representation.

4. The discipline is based on a positive approach with rewards and sanctions.

For the UK's teachers who do not have a discipline plan, the feeling of their approaches on discipline can be summarized as follows:

1. Teachers vary strategies should consider the class of themselves and children's age and individual children's needs.

2. Teachers try to be positive whenever they can.

3. "Praise" stickers work well with children as it is an immediate reward and others (children and adults) can see it. Therefore, many teachers introduce their reward system. One type of it calls "table point" 
which can be gained or lost. Teachers give "table point" to children, with their own good behaviours on it. When they do not keep this good behaviour, they will lose it. Therefore, this reward system is linked to punish system.

\section{Conclusion}

To conclude, the biggest difference about discipline plan is that no Chinese teachers having it while most of the UK's teachers making it. Perhaps this is because in Chinese primary schools, teachers do not have this tradition. It is the difference of schools in two countries. Although some of Chinese primary school teachers have already known about the importance of discipline plan, they do not change it. The purpose of a classroom discipline plan is to avoid the need for teachers to make hasty, illconsidered or emotionally charged responses to students' disruptions, resulting in inconsistent or arbitrary reactions (Canter, 2001). A plan also enables teachers to secure support from parents and school administrators. It will consist of the three elements of rules, supportive feedback and corrective actions for noncompliance (Canter, 2001). The UK's teachers have some good examples for Chinese teachers. So Chinese primary schools need to learn to make discipline plans, especially the new teachers. On this aspect, the UK's situation is better than China, as most of the teachers make discipline plan.

The second difference is that the UK's teachers consider some important factors such as children's age, the situation of their classroom and the individual' needs when they approach to discipline problems. In contrast, the Chinese teachers do not pay attention to it. However, it is important for teachers because it can help teachers solve the problems easily and successfully. Under different circumstance, teachers need the most suitable strategies.

Another difference is that Chinese teachers want to solve the discipline problems by changing children's attention, while the UK's teachers do not refer to it. However, in fact, this strategy is not successful in those teachers' experience. This finding is consistent with Yu's description in 2003. He suggests teachers should not only focus on the interest of class, they also need to combine the teaching activities to the behaviour management.

For Chinese teachers, it is possible that they are used to require children to obey rules. Compared with it, teachers in the UK internalize requirements into children's own business. For example, they let children making their own rules. Furthermore, the UK's teachers have more flexible strategies on discipline. Different systems such as reward system and warning system are examples. Generally speaking, the strategies such as "table point" account for teachers' intelligence. They integrate a big system, and under this system, different branches on the basis of the practice are born.

On the other hand, there are some similarities between the two countries on their practice or feelings on discipline. First of all, some strategies and ideas on solving discipline problems are similar. For example, both Chinese and the UK's primary school teachers care about children's self-esteem. Facing children's problems, they do not treat it as a terrible issue, nevertheless, as a common phenomenon. Secondly, self-discipline is used universally in teachers' approaches. The most significant evidence is setting up the role of example. They encourage children to restrain their own behaviours. Teachers pay attention to children's changing in different period, not the comparison among children. It may explain that teachers become more positive when they face the problems.

Overall, there are both similarities and differences between the two countries. First of all, most of teachers maintain discipline for the purpose of helping students establish self- discipline, which is related to the cognitive discipline theory. Secondly, the behaviours that may influence other pupils or the whole class are high priorities for teachers to correct. For example, students cannot keep quiet when teacher is talking. Thirdly, a large number of teachers prefer eye contact when they discovery the misbehaviours of children, meanwhile, they consider this approach is very effective for them. Another effective approach for them is changing student's seat nearby them. They do not ignore the problems when they attention the discipline problems because they treat it as the most ineffective solution. Fourth, all of them have the strategies when they approach discipline problem. Fifth, they pay attention to children's self-esteem and prefer the role of good examples. For instance, they praise others who have a good behaviour in class.

On the other hand, the differences also exist. Firstly, Chinese teachers maintain discipline for four different goals while the UK's teachers only for two goals. Furthermore, order and self-discipline is 
distributed nearly equal in China while nearly all the teachers prefer self-discipline in the UK. Secondly, compared with the UK's teachers, teachers' authority is more important for Chinese teachers. Thirdly, the UK's teachers do better on discipline plan and considering the factors on individual's characteristics and the practice circumstance when they need to approach discipline problems.

However, the similarities are more than the differences between the two countries. The reasons for the similarities and differences may be concluded as follows:

Firstly, the different beliefs of children's behaviours influence teachers' definitions about children's misbehaviours. If the teachers in two countries have the same beliefs, they may have the consistent attitudes when they solve the discipline problems.

Secondly, globalization may bring about the communication of two countries. Global education is one part of globalization. China and the UK can communicate their education ideas, practice and experience through different methods such as exchange students. Therefore, the good experience and strategies can be shared in the two countries.

Thirdly, cultural differences may cause the differences. In China, the culture prefers compliance or obedience, especially in the relation between elder and younger or leader and staff or teachers and students. Therefore, teachers care more about their authority in China, where compared with the UK.

Fourth, the different practice situation may lead to the differences. In the schools or classes in two countries, children's characteristics, class size, children's behaviours and other factors may be different, so teachers' attitude, approaches or strategies are different.

Lastly, the education system may be related to the differences between the two countries. There are different subjects in Chinese primary schools and this factor influences teachers' goal on maintaining discipline and their approaches.

Therefore, many factors may influence teachers' attitude, approaches and idea on maintaining discipline. China and the UK have both similarities and differences on teachers' approaches to discipline and there are different factors causing them.

To conclude, this study has mostly solved the research questions many aspects, but not all the aspects. There are some limitations in methodology and findings, which will be improved in further research.

\section{References}

1. Achenbach, T.M., Dumenci, L., \& Rescorla, L.A. (2002). Is American student behavior getting worse? : teacher ratings over an 18-year period. School Psychology Review, vol. 31, no. 3, pp. 428-42.

2. Alberto, P. A., \& Troutman, A.C. (2003). Applied behavior analysis for teachers. Upper Saddle River: Merrill Prentice Hall.

3. Bauer, G.L. (1985). Restoring order to the public schools. In Phi Delta kappa (Eds.), Discipline in schools (pp. 488-491). New York, The USA: Wiley

4. Biou-Nakou, I., Kiosseoglou, G. \& Stogiannidou, A. (2002). Elementary teachers' perceptions regarding school behavior problems: implications for school psychological services. Psychology in the schools, vol. 37, no. 2, pp. 123-34.

5. Bogdan, R.C., \& Bilkev, S.K. (2005). Qualitative Research for Education: An Introduction To Theories and Models. California, The USA: Anchor Books- Doubleday.

6. Canter, L. \& Canter, M. (1992). Assertive discipline: positive behavior management for today's classroom. Santa Monica, The USA: Lee Canter \& Associates.

7. Canter, L. \& Canter, M. (2001). Assertive discipline: positive behavior management for today's classroom. Los Angeles, The USA: Canter and Associates.

8. Cleary, T.J. \& Zimmerman, B.J. (2004). Self-regulation empowerment program: a school- based program to enhance self-regulated and self-motivated cycles of student learning. psychology in the schools, vol. 41, no. 1, pp. $1-35$.

9. Dahlberg, G., Moss, P., \& Pence, A. (1999). Beyond quality in early childhood education and care: postmodern perspectives. London: Routledge Falmer.

10. Denzin, N.K. (1978). The Research Act. New York, The USA: McGraw-Hill.

11. Elam, S.M., Rose, L.C., \& Gallup, A.M. (1991). The 23rd annual gallup poll of the public's attitudes toward the public schools.In Phi Delta Kappan (Eds.), Discipline in schools (pp. 41-56). New York, The USA: Wiley. 
12. Fraser, S., \& Gestwicki, C. (2002). Authentic childhood: exploring Reggio Emilia in the classroom. Albany: Delmar.

13. Gartrell, D. (2003). A guidance approach for the encouraging classroom. New York, the USA: Delmar.

14. Glasser, W. (1998a). The quality school: managing students without coercion. New York, The USA: HarperPerennial.

15. Glasser, W. (1998c). Choice theory: a new psychology of personal freedom. New York, The USA: HarperCollins.

16. Gordon, T. (1970). Parent effectiveness training. New York: Plume.

17. Gordon, T. (1974). Teacher effectiveness training. New York: Peter H. Wyden.

18. Goodenow, C. (2004). Classroom belonging among early adolescent students: relationships to motivation and achievement. Journal of Early Adolescence, vol. 13, no. 1, pp. 21-43.

19. Hallahan, D.P., \& Kauffman, J.M. (2003). Exceptional learners: introduction to special education. Boston: Allyn \& Bacon.

20. Hart, J.E., \& Lordon, J.F. (1978). School Discipline: Yesterday, Today, and Tomorrow. The Clearing House, vol. 52, No. 2, pp. 68-71. Retrieved September 1, 2010, from http://www.jstor.org/stable/30185093

21. Hartzell, G.N., \& Petries, T.A. (1992). The Principal and Discipline: Working with School Structures, Teachers and Students. The Clearing House, vol. 64, no. 6, pp. 376-380. Retrieved August 2, 2010, from http://www.jstor.org/stable/30185841

22. Jick, T.D. (1979). Process and Impacts of a Merger: Individual and Organizational Perspectives. New York State School of Industrial ND labor Relations, Cornell University: Doctoral dissertation.

23. Johnson, L.V., \& Bany, M.A. (1970). Classroom management: Theory and skill training. New York, The USA: Macmillan.

24. Kendall, P.C. (2000). Child and adolescent therapy: cognitive-behavioral procedures. New York, The USA: Guilford.

25. Knoff, H. M. (1983). Solving school discipline problems: look before you leap!. The Clearing House, vol. 57, No. 4, pp. 155-157. Retrieved August 31, 2010, from http://www.jstor.org/stable/30186267

26. Kohn, A. (1996a). Beyond discipline: from compliance to community. Association for Supervision and Curriculum Development. Alexandria: VA.

27. Lee, N. (2001). Childhood and society: growing up in an age of uncertainty. Buckingham: Open University Press.

28. Liu, J. B. (1998). The socialization of Children. Beijing, China: China Education Press.

29. MacNaughton, G. (2003). Shaping early childhood learners, curriculum and contexts. Berkshire: Open University Press.

30. Maslow, A.H. (1968). Toward a psychology. Van Nostrand, Princeton: NJ.

31. Mayall, B. (2002). Towards a sociology of childhood: thinking from children's lives. Buckingham: Open University Press.

32. Miller, A. (2003). Teachers, parents and classroom behaviour: a psychosocial approach. Maidenhead: Open University Press.

33. Miller, A., Ferguson, E., \& Byrne, I. (2000). Pupils' causal attributions for difficult classroom behaviour. British Journal of Educational Psychology, vol. 70, no. 1, pp. 85-96.

34. Miller, A., Ferguson, E. \& Moore, E. (2002). Parents' and pupils' causal attributions for difficult classroom behaviour. British Journal of Educational Psychology, vol. 72, no. 1, pp. 27-40.

35. Montgomery, H. (2003). Childhood in time and place. In M. Woodhead E H. Montgomery (Eds.). Understanding childhood: an interdisciplinary approach (pp. 45-83). UK: Open University Press.

36. Mortimore, P., Sammons, P., Stoll, L., Ecob, R., \& Lewis, D. (1998). The effects of school membership on pupils' outcomes'. Reserch Papers in Education, vol. 3, no. 1, pp. 52-53.

37. Mortimore, P., Sammons, P., Stoll, L., Ecob, R. \& Lewis, D. (1998). The effects of school membership on pupils' outcomes. Research Papers in Education, vol. 3, no. 1, pp. 3-26.

38. Myers, C.L., \& Holland, K.L. (2000). Classroom behavioral interventions: do teachers consider the function of the behavior? Psychology in the Schools, vol. 37, no. 3, pp. 271-80.

39. Osterman, K.F. (2000). Students' need for belonging in the school community. Review of Educational Research, vol. 70, no. 3, pp. 323-6\%.

40. Porter, L. (1999). Behaviour management practices in child care centres' unpublished doctoral dissertation. Adelaide, Australia: University of South Australia.

41. Porter, L. (2003). Young children's behaviour: practical approaches for caregivers and teachers. Sydney, Australia: Paul Chapman.

42. Porter. L. (2006). Behaviours In Schools. Berkshire: Open University Press. 
43. Porter, L. (2006). Children are people too: a parent's guide to young children's behaviour. Adelaide, Australia: East Street Publications.

44. Raskin, N.J. \& Rogers, C.R. (2005). Person-centered therapy. In R.J. Corsini 8 D. wedding (Eds). Current psychotherapies (pp. 130-65). Thomson Brooks/Cole, Belmont: CA.

45. Roffey, S., \& O'Reirdan, T. (2001). Young children and classroom behaviour: needs, perspectives and strategies. London: David Fulton.

46. Rogers. B. (2006). Classroom Behaviour. London: Book Education 2000.

47. Rogers, W.S. (2003). What is a child? In M. Woodhead \& H. Montgomery (Eds.). Understanding childhood: an interdisciplinary approach (pp. 1-43). UK: Open University Press.

48. Rutter, M. (1983). School effects on pupil progress: research findings and policy implications. Child Development, vol. 18, no. 3, pp. 313-52.

49. Rutter, M. \& Maughan, B. (2002). School effectiveness findings 1979- 2002. Journal of School Psychology, vol. 21, no. 2, pp. 119-44.

50. Sylva, K. (1994). School influences of children's development. Journal of child Psychology and Psychiatry and Related Disciplines, vol. 35, no. 1, pp. 135-70

51. Thomas. R. M. (2003). Blending qualitative $\&$ quantitative research methods in theses and dissertations. The USA: Wiley

52. Wolfgang. C. H. (1999). Solving Discipline Problems. John Wiley \& Sons, Inc.

53. Xu, Z.Y. (2000). Know Children again. Jiangsu, China: Nanjing Normal University Press.

54. Yu, Y.P. (2000). Curriculum evaluation. Jiangsu, China: Feng huang Press.

55. Yu, Y.P. (2006). Discipline in Class. Jiangsu, China: Jiangsu Education Press. 